\title{
Effect of varying the proportion of concentrate with the same starch content in the diet on passage rate and on ruminal digestion in dairy cows
}

\author{
BP Widyobroto, JL Peyraud \\ INRA, station de recherche sur la Vache laitière, 35590 Saint-Gilles, France
}

The mean retention time (MRT) of feed particles increases with the amount of cereal-based concentrate in the diet. However, there is a danger of confusion between this effect and an increase of starch content. This experiment studies the effect of the proportion of concentrate with the same starch: NDF ratio in the diet.

Three diets with a different level of concentrate $(20,35,50 \%$ DM) but the same starch $(31 \%)$ and NDF content $(38 \%)$ were studied in a latinsquare design using 6 fistulated cows. The 3 diets were fed ad libitum and consisted of maize silage and a concentrate (30\% beet pulp, $25 \%$ wheat bran, $10 \%$ dehydrated lucerne, $35 \%$ cereals). The ruminal outflow rate of liquid ( $\mathrm{KI}$ ) was estimated by PEG dilution. The duodenal flow and the rate of passage of Eu-labelled maize silage and Dy-labelled concentrate were measured simultaneously. The flow was calculated from PEG and $Y b$ recovered in faeces. MRT of forage (MRTF) and concentrate (MRTC) in the digestive tract were calculated from the quantities of Eu and Dy excreted at each collection interval.

Organic matter intake (OMI) increased with the proportion of concentrate and this was related to an increase in milk production (from 31.9 to $35.3 \mathrm{~kg} / \mathrm{d}$ ). OM digestibility did not vary $(0.69)$ but NDF digestibility was slightly reduced (from 0.59 to 0.57 $P<0.05)$ with the highest level of concentrate. The 3 treatments had no effect $(P>0.10)$ on the proportion of digestible OM or digestible NDF apparently digested in the rumen (RNDF) or on the NAN flow into the duodenum. Their values were $0.55,0.85$ and $43.6 \mathrm{~g} / \mathrm{Kg}$ DOM respectively. MRTF, MRTC and KI were not significantly $(P>0.10)$ affected by the level of concentrate despite the $\mathrm{OMI}$ variations. $\mathrm{KI}$ and MRT showed large between-cow variations which were correlated $(P<0.10)$ with individual variation in RNDF (varying from 0.75 to 0.95 ); lower RNDF was observed in cows with a faster rate of passage.

This experiment suggests that increasing the proportion of concentrate in a maize silage diet may not substantially affect the extent and site of digestion, provided starch content is not greatly modified.

Table I. Effect of the proportion of concentrate in the diet on some parameters of the passage rate of digesta

\begin{tabular}{lllll}
$\begin{array}{l}\text { Concentrate } \\
(\%)\end{array}$ & $\begin{array}{l}\text { OMI } \\
(\mathrm{Kg} / \mathrm{d})\end{array}$ & $\begin{array}{l}\text { MRTF } \\
(\mathrm{h})\end{array}$ & $\begin{array}{l}\text { MRTC } \\
(\mathrm{h})\end{array}$ & $\begin{array}{l}K \mathrm{~K} \\
(\% / h)\end{array}$ \\
\hline & & & & \\
20 & $19.4^{\mathrm{a}}$ & 50.8 & 39.0 & 11.3 \\
35 & $20.1^{\mathrm{ab}}$ & 52.0 & 37.4 & 11.4 \\
50 & $21.4^{\mathrm{b}}$ & 51.2 & 36.7 & 11.1
\end{tabular}
a,b Means with different superscripts in the same co-
lumn are significantly different $(P<0.05)$. 